Bruno Exposto, J. G. Pinto, Delfim Pedrosa, Vitor Monteiro, Henrique Gonçalves, João L. Afonso, "Current-Source Shunt Active Power Filter with Periodic-Sampling Modulation Technique", 38th Annual Conference of the IEEE Industrial

Electronics Society - IECON2012, pp. 1274-1279, Montreal, Canada, Oct. 2012, ISBN: 978-1-4673-2420-5.

\title{
Current-Source Shunt Active Power Filter with Periodic-Sampling Modulation Technique
}

\author{
Bruno Exposto, J. G. Pinto, Delfim Pedrosa, Vitor Monteiro, Henrique Gonçalves, João L. Afonso \\ Centro Algoritmi - University of Minho \\ Guimarães, Portugal \\ bruno.exposto@algoritmi.uminho.pt, gabriel.pinto@algoritmi.uminho.pt, delfim.pedrosa@algoritmi.uminho.pt, \\ vitor.monteiro@algoritmi.uminho.pt, henrique.goncalves@algoritmi.uminho.pt, joao.l.afonso@algoritmi.uminho.pt
}

\begin{abstract}
In this paper are presented experimental and simulation results of a developed Current-Source Three-Phase Shunt Active Power Filter compensating the currents of a nonlinear load. The Shunt Active Power Filter controller, described in detail along the paper, relies in the $p-q$ Theory to calculate the reference compensation currents and to regulate the DC-link inductance current. The regulation of the active filter DC-link inductance current is done consuming sinusoidal currents in phase with the system voltages. The performance and the dynamic behavior of the Shunt Active Power Filter using Periodic Sampling Modulation Technique was assessed first through several computer simulations, and then through the analysis of experimental results obtained with a developed laboratory prototype. Thereby, in this paper are presented several obtained results that show the correct operation of a Current-Source Three-Phase Shunt Active Power Filter using the Periodic-Sampling Modulation Technique.
\end{abstract}

\section{INTRODUCTION}

Electrical Power Quality is probably the most important issue in modern electrical grids. Low Power Quality, costs more than $€ 150$ billion a year to business in Europe [1]. Therefore Electrical Power Quality improvement represents for companies lower costs, productivity increasing, efficiency increasing, and less equipment malfunction.

In recent years is being made an effort to address the Electrical Power Quality problems, and consequently several power electronics solutions have been developed. One of the most innovative solutions are the Shunt Active Power Filters [2]. There have been presented several types of these power electronics devices and their improvement is notorious [3], [4]. There are several topologies of Shunt Active Filters, but they can be generally classified in two main groups: Voltage-Source Active Filters and Current-source Active Filters.

An extensive work has already been made in Active Power Filters that use voltage-source inverters, but the use of current-source inverters in these equipment, can still be object of further improvements and developments.

Current-source inverters have been used in several applications such as motor drives [5], renewable energy grid connection systems [6], and as referred before, Shunt Active Filters [7].
Current-Source Active Filters present several advantages, namely: excellent current control, easy protection, high reliability and high efficiency also with low power loads [7]. The fact that in the DC side there is an inductance is also an advantage relatively to Voltage-Source Active Filters, because the lifetime of an inductance is superior to the lifetime of a capacitor.

The main disadvantages of this type of active filter are the bulky DC link inductor, the high DC-link inductor losses, the overvoltage protection circuit that is necessary to protect the inverter, and the slow dynamics inherent to this type of inverter [8]. Nevertheless, as has been said before, the use of current-source inverters can still be much explored in the area of solving Power Quality problems.

In this paper are presented simulation and experimental results of a Current-Source Shunt Active Filter operating with periodic-sampling modulation technique. The reference currents generation and control of the Current-Source Active Filter is done using the $p-q$ Theory. The active filter DC-link current regulation is also done with the $p-q$ Theory, and with a PI controller.

\section{CURRENT-Source SHUNT ACtive Power Filter TOPOLOGY}

The topology of the developed Shunt Active Power Filter is constituted by a three-phase three-wire current-source inverter (Fig. 1). In the DC-link of the inverter was placed an inductor. This inductor has a large size, which is necessary to keep the DC-link current $\left(i_{d c}\right)$ ripple low, so that the inverter produced currents $\left(i_{f x}\right)$ are not affected. The proposed topology uses 6 IGBTs in series with diodes. The diodes are placed in series with the IGBTs because the IGBTs do not have reverse-blocking capability. In the output of the inverter were placed LC low-pass filters, to filter the compensation currents produced by the active filter. These passive filters were dimensioned to minimize the inverter switching noise, and to maximize the bandwidth, so that the Current-Source Shunt Active Filter can also compensate high harmonic order components of the load currents. 


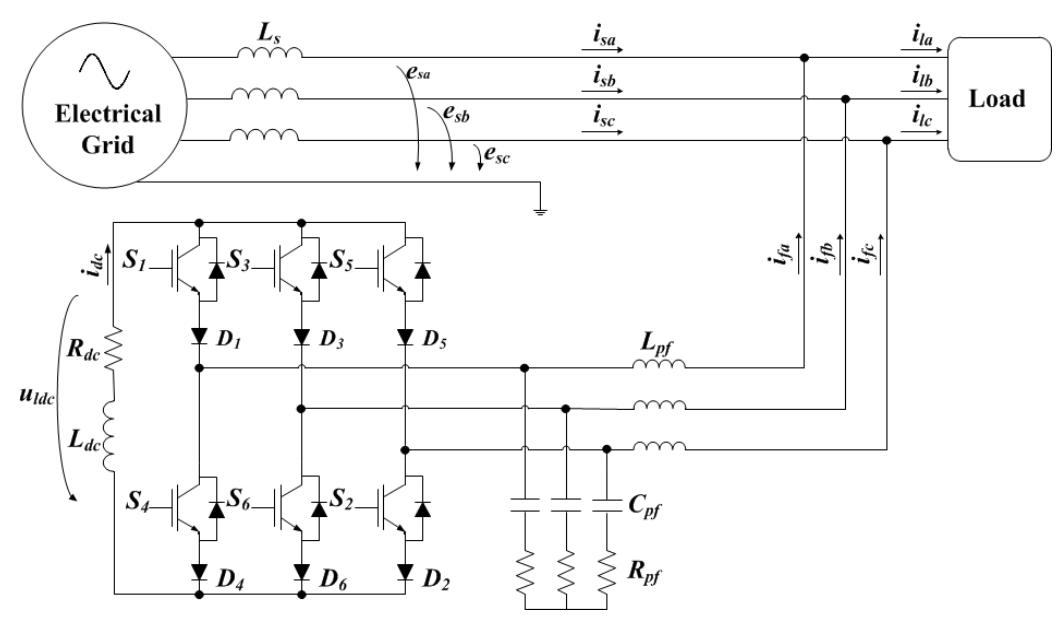

Fig. 1. Current-Source Shunt Active Power Filter topology.

The transfer function of the LC low-pass passive filter is described by (1). The resonance frequency of the passive filter is given by (2).

$$
\begin{gathered}
\frac{I_{f x}}{I_{\text {in }}}=\frac{1 / L C+(R / L) s}{1 / L C+(R / L) s+s^{2}} \\
f_{r}=1 /(2 \pi \sqrt{L C})
\end{gathered}
$$

Keeping in mind that the adopted switching technique is Periodic-Sampling, the values of the passive filter were adjusted to get the maximum performance, i.e., lower THD in the compensated currents. In Table I are presented the parameters of the passive filter. In Fig. 2 can be seen the frequency response (gain and phase) of the passive filter.

TABLE I

PARAMETERS OF THE LC LOW PASS FILTER.

\begin{tabular}{|c|c|}
\hline $\begin{array}{c}\text { Passive } \\
\text { Filter } \\
\text { Parameters }\end{array}$ & Value \\
\hline $\boldsymbol{C}_{\boldsymbol{p f}}$ & $30 \mu \mathrm{F}$ \\
\hline $\boldsymbol{L}_{\boldsymbol{p f}}$ & $5 \mathrm{mH}$ \\
\hline $\boldsymbol{R}_{\boldsymbol{p f}}$ & $4.7 \Omega$ \\
\hline $\boldsymbol{f}_{\boldsymbol{r}}$ & $410 \mathrm{~Hz}$ \\
\hline
\end{tabular}

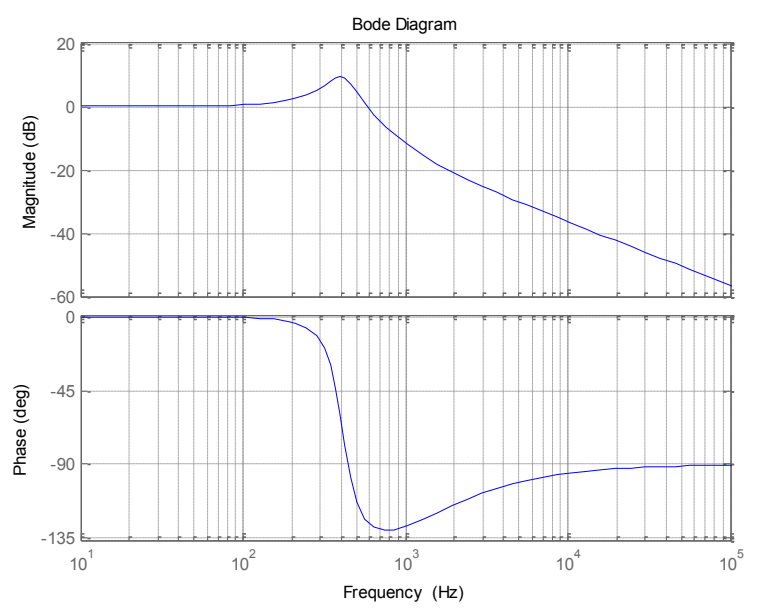

Fig. 2. Passive filter frequency response.

\section{Periodic SAmpling Switching TeChNique}

There are several switching techniques that can be used in Shunt Active Power Filters, namely space-vector modulation and carrier-based pulse width modulation [8],[9]. However, in this case was implemented the Periodic-Sampling modulation technique. Although the current THD of this switching technique is higher than the current THD of other switching techniques, and the switching frequency is not clearly defined [10], [11], the implementation of this switching technique is simple and effective.

To implement the Periodic-Sampling switching technique (Fig. 3) was used a combinational logic circuit, similar to that is referred in [11], that generates the pulse patterns that respect the inverter valid states. The switching pulses are generated comparing the reference compensating currents $\left(i_{c a^{*}}, i_{c b^{*}}, i_{c c^{*}}\right)$ with the inverter currents $\left(i_{f a}, i_{f b}, i_{f c}\right)$ and the result of this comparison is sent to a combinational logic circuit.

It must be referred that the inverter switching states must never interrupt the DC-link inductor current [9], otherwise can occur overvoltages in the DC-link inductor that can damage the inverter power semiconductors.

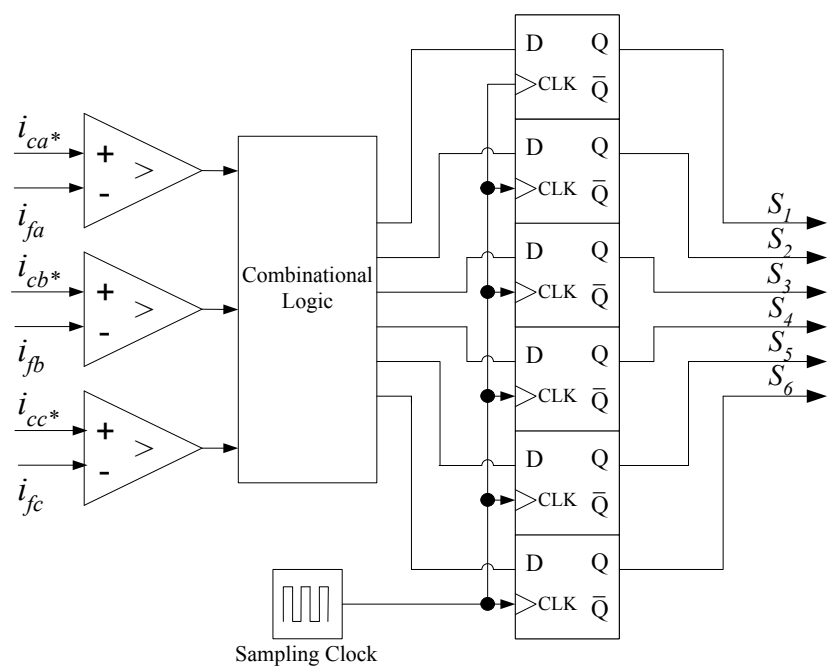

Fig. 3. Periodic-Sampling switching pattern generator. 


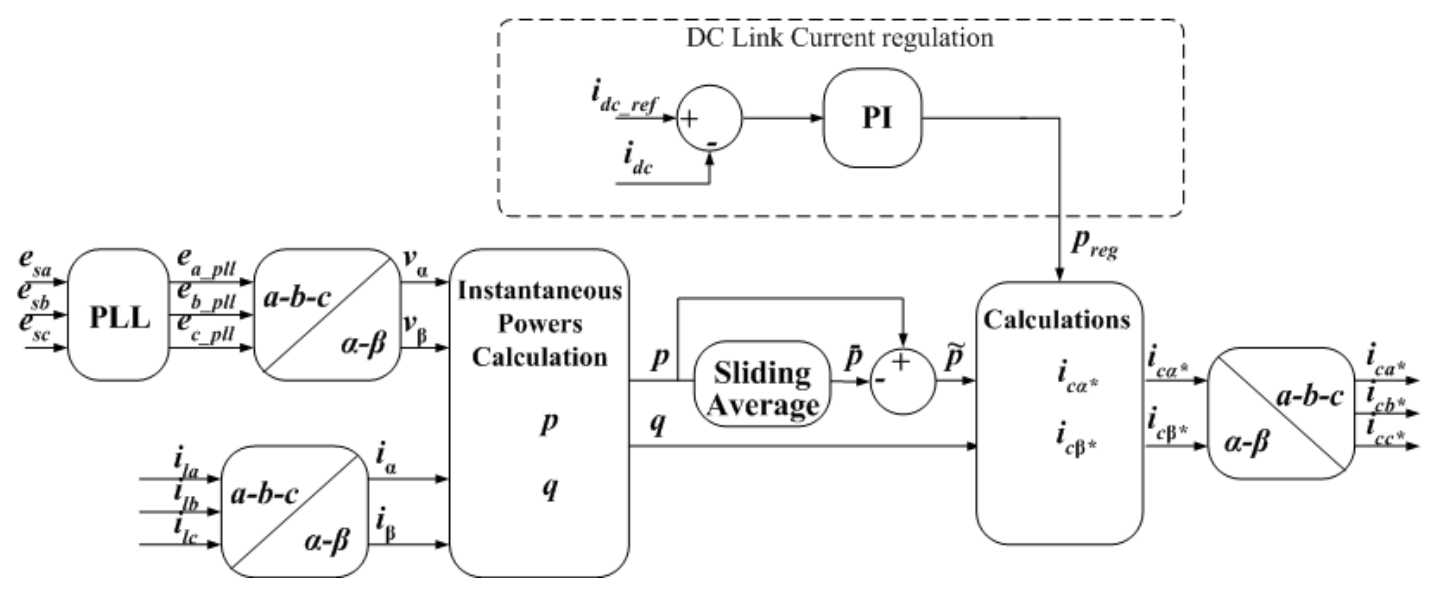

Fig. 4. Current-Source Active Power Filter control theory.

\section{CONTROL THEORY}

The digital control system of the Shunt Active Power Filter described in this paper is based on the $p-q$ Theory proposed by Akagi et al. [12]. This theory has been largely used in Voltage-Source Active Power Filters [13],[14],[15]. Nevertheless, in Current-Source Active Power Filters the application of the $p-q$ Theory is restricted.

The DC-link current regulation is also done using the $p-q$ Theory and a PI controller.

\section{A. $p-q$ Theory}

During the simulations and the implementation of the Current-Source Active Power Filter, the $p-q$ Theory was implemented to work as the "Sinusoidal Source Currents" algorithm [14]. To perform this task was implemented a Phase-Lock Loop Circuit (PLL) that extracts the positive sequence values of the system voltages fundamentals $\left(e_{a \_p l l}, e_{b \_p l l}, e_{c \_p l l}\right)$.

The values of those voltages and of the load currents are converted to a $\alpha-\beta$ reference frame applying the appropriate $\alpha-\beta$ transformation, (3) and (4), respectively:

$$
\begin{gathered}
{\left[\begin{array}{c}
v_{\alpha} \\
v_{\beta}
\end{array}\right]=\sqrt{2 / 3} \cdot\left[\begin{array}{ccc}
1 & -1 / 2 & -1 / 2 \\
0 & \sqrt{3} / 2 & -\sqrt{3} / 2
\end{array}\right] \cdot\left[\begin{array}{c}
e_{a_{-} p l l} \\
e_{b_{-} p l l} \\
e_{c} p l l
\end{array}\right]} \\
{\left[\begin{array}{c}
i_{\alpha} \\
i_{\beta}
\end{array}\right]=\sqrt{2 / 3} \cdot\left[\begin{array}{ccc}
1 & -1 / 2 & -1 / 2 \\
0 & \sqrt{3} / 2 & -\sqrt{3} / 2
\end{array}\right] \cdot\left[\begin{array}{l}
i_{a} \\
i_{b} \\
i_{c}
\end{array}\right]}
\end{gathered}
$$

The instantaneous real power, $p$, and the instantaneous imaginary power, $q$, are calculated in the $\alpha-\beta$ reference frame using $v_{\alpha}, v_{\beta}, i_{\alpha}$ and $i_{\beta}(5)$.

$$
\left[\begin{array}{c}
p \\
q
\end{array}\right]=\left[\begin{array}{cc}
v_{\alpha} & -v_{\beta} \\
v_{\beta} & v_{\alpha}
\end{array}\right] \cdot\left[\begin{array}{c}
i_{\alpha} \\
i_{\beta}
\end{array}\right]
$$

Then, through a sliding average algorithm, is obtained the mean value of the instantaneous real power $(\bar{p})$. The sliding average algorithm was implemented with a windows correspondent to one grid cycle. Using $p$ and $\bar{p}$ is possible to obtain the alternating value of the instantaneous real power $(\tilde{p})$.

Then the values of the $p_{\text {reg }}$ and the $q$ are used to calculate the reference compensating powers $p_{x}$ and $q_{x}$ (6) (7). $p_{\text {reg }}$ is a real power that is necessary to regulate the DC-link current, and in steady state it is proportional to the inverter losses.

$$
\begin{gathered}
p_{x}=\tilde{p}-p_{\text {reg }} \\
q_{x}=q
\end{gathered}
$$

Using $p_{x}$ and $q_{x}$ it is possible to determine, in the $\alpha-\beta$ reference coordinates, the reference compensating currents, which shall be generated by the Current-Source Shunt Active Power Filter inverter (8).

$$
\left[\begin{array}{l}
i_{c \alpha} \\
i_{c \beta}
\end{array}\right]=\frac{1}{v_{\alpha}{ }^{2}+v_{\beta}{ }^{2}} \cdot\left[\begin{array}{cc}
v_{\alpha} & -v_{\beta} \\
v_{\beta} & v_{\alpha}
\end{array}\right] \cdot\left[\begin{array}{l}
p_{x} \\
q_{x}
\end{array}\right]
$$

The compensating reference currents in $\alpha-\beta$ coordinates, $i_{c \alpha}$ and $i_{c \beta}$, are then converted to the $a-b-c$ coordinates system, and are used in the modulator to compare them with the inverter generated currents. After determining the compensation reference currents $\left(i_{c a^{*}}, i_{c b^{*}}, i_{c c^{*}}\right)$, their values are compared with the Active Filter compensating currents $\left(i_{f a}, i_{f b}, i_{f c}\right)$, and the result is sent to a combinational logic circuit that generates the pulse patterns of the PeriodicSampling modulation technique [11].

In Fig. 4 is shown the block diagram of the digital control system. As presented in this figure, the DC-link inductor current is controlled by a Proportional-Integral (PI) controller that generates a $p_{\text {reg }}$ signal, which is proportional to the error between the reference to the DC-link current and the measured current. Because the DC-link current reference is fixed, it is necessary to previously determine the amplitude of the loads currents that will be compensated, in order to adjust the value of the DC-link current reference. The DC-link 
current must be higher than the peak of the inverter output currents. Other possibility to control the current in the DC-link is based on a dynamic adjustment of the reference current to regulate the DC-link current accordingly to the load current consumption. However, in the results presented in this paper, the DC current reference is kept constant, and must be adjusted accordingly with the load that the Shunt Active Power Filter will compensate.

\section{Simulation RESUlts}

The simulated inverter topology of the Current-Source Shunt Active Power Filter is the same depicted in Fig. 1. The simulations were done using the software PSCAD from Manitoba HVDC Research Centre Inc, and were done considering real values for the simulation parameters. The Active Power Filter and the loads were connected to three-phase $400 / / 200 \mathrm{~V} 50 \mathrm{~Hz}$ transformer to simulate the same conditions that will applied in the laboratorial prototype. The simulated load is a full-bridge rectifier, with resistive-inductive load (a nonlinear load). In series with the rectifier were placed three inductances with the value of $5 \mathrm{mH}$. In Table II are presented the values of the parameters used in the simulation model.

The Current-Source Shunt Active Power filter was simulated using Periodic-Sampling as modulation technique, and the sampling frequency was fixed in $16 \mathrm{kHz}$.

In Fig. 5 are shown the simulation results of the Active Power Filter when compensating the currents of a non-linear load. As it can be seen, before the compensation (Fig. 5 (a)) the source current of ph. $\left(e_{s a}\right)$ are also distorted. With the operation of the Active Power Filter, which generates adequate compensating currents (Fig. 6), the source current of phase $a\left(i_{s a}\right)$ acquire a nearly sinusoidal waveform, as shown in Fig. 5 (b).

In Fig. 7 is possible to see the DC-link current. This current is regulated to $5 \mathrm{~A}$, which corresponds to the peak of the reference compensating currents plus the part correspondent to the losses of the inverter. In this way the inverter operates in the linear zone. This current presents a small ripple that is characteristic of the type of load that the Current-Source Active Filters is compensating.

TABLE II

Parameter Values of the Simulation Model.

\begin{tabular}{|c|c|c|c|c|}
\hline Parameters & Value & Load & Parameters & Value \\
\hline$e_{s}$ & $200 \mathrm{~V} 1-1$ & \multirow{3}{*}{$\begin{array}{l}\text { Full Bridge } \\
\text { Rectifier }\end{array}$} & $\boldsymbol{R}_{d c}$ & $26 \Omega$ \\
\hline$L_{s}$ & $1.1 \mathrm{mH}$ & & $L_{d c}$ & $146 \mathrm{mH}$ \\
\hline $\boldsymbol{R}_{s}$ & $0.01 \Omega$ & & $\boldsymbol{L}_{\text {series }}$ & $5 \mathrm{mH}$ \\
\hline$L_{d c}$ & $128 \mathrm{mH}$ & & & \\
\hline $\boldsymbol{R}_{d c}$ & $0.46 \Omega$ & & & \\
\hline$C_{p f}$ & $30 \mu \mathrm{F}$ & & & \\
\hline$L_{p f}$ & $5 \mathrm{mH}$ & & & \\
\hline $\boldsymbol{R}_{p f}$ & $4.7 \Omega$ & & & \\
\hline$f_{s}$ & $16 \mathrm{kHz}$ & & & \\
\hline
\end{tabular}

Nevertheless is possible to see that the implemented PI controller is performing well.

Fig. 8 shows the voltage spikes that appear in the DC-link inductance associated with the fluctuation of the DC-link current.
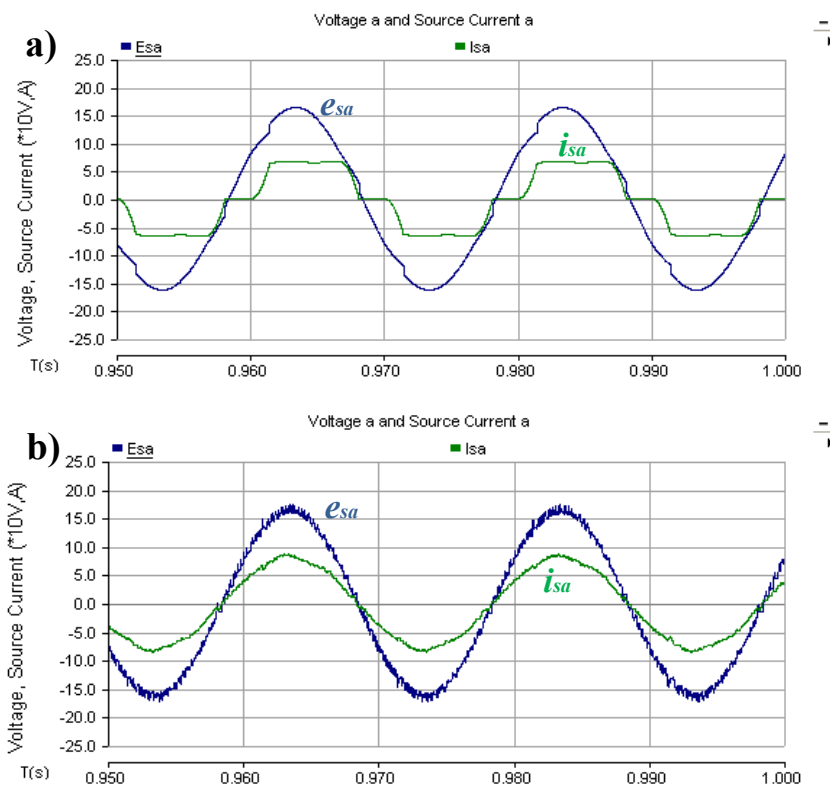

Fig. 5. Simulation results of the voltage $\left(e_{s a}\right)$ and source current $\left(i_{s a}\right)$ before the compensation (a) and after the compensation (b).

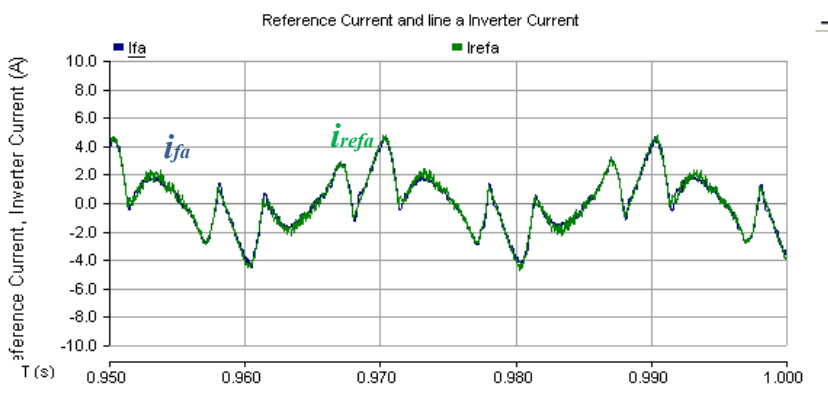

Fig. 6. Simulation results of the inverter reference current $\left(i_{\text {refa }}\right)$ and inverter produced current $\left(i_{f a}\right)$.

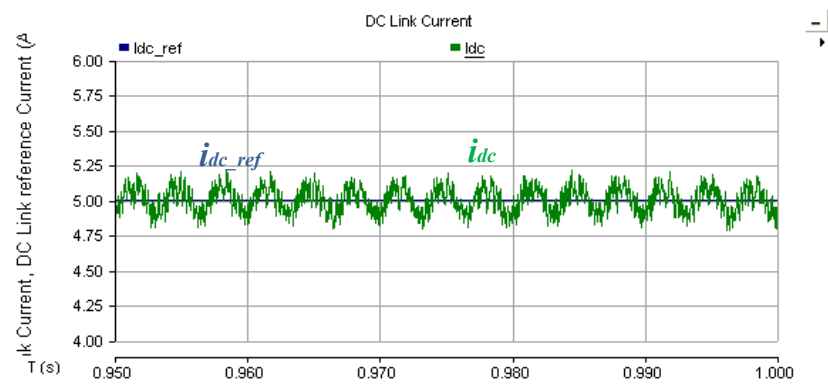

Fig. 7. Simulation results of the DC-link reference current $\left(i_{d c_{-} r e f}\right)$ and DClink current $\left(i_{d c_{-} r e f}\right)$. 


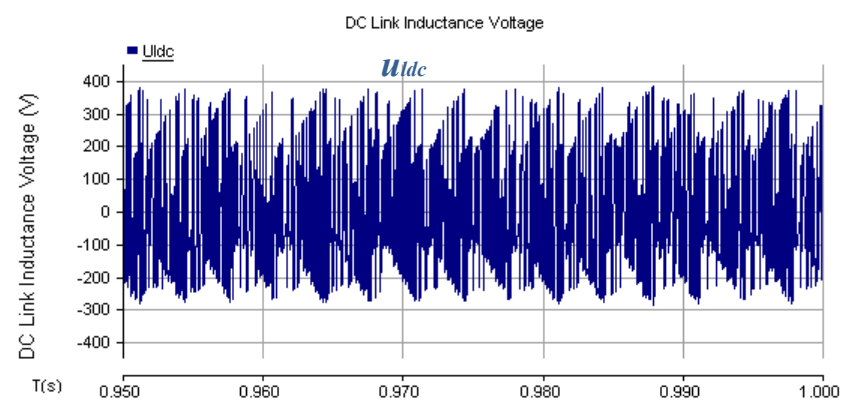

Fig. 8. Simulation results of the DC-link inductance voltage $\left(v_{l d c}\right)$.

\section{EXPERIMENTAL RESULTS}

To evaluate the designed and simulated Current-Source Active Power Filter under real conditions of operation, it was developed and built a laboratory prototype of the Active Filter. The prototype can compensate Power Quality problems associated with the load currents, such as harmonics and power factor, with compensation currents up to $10 \mathrm{~A}$ peak. The developed laboratory prototype is divided in two fundamental parts: the power electronics hardware and the digital control system.

The power electronics hardware is constituted by the Current-Source inverter topology that is depicted in Fig. 1. For this propose was used discrete IGBTs and diodes. In the DC-link was placed an inductance with the nominal value of $L_{d c}=128 \mathrm{mH}$.

The digital control system is composed by a Texas Instruments TMS320F2812 DSP in which was implemented the $p-q$ Theory and the other parts of the control system such as a Phase-Locked Loop and the DC-link current control. It was also used a combinational logic circuit, a Generic Array Logic (GAL) that generates the pulse patterns to the IGBTs making the interface between the DSP and the inverter. In this GAL was also implemented a logic circuit that inhibits the inverter switching pulses on the user demand. It was also implemented a signal conditioning circuit that receives the measured signals from the Hall-effect current and voltage sensors, and that adjust these signals to the range of values of the DSP ADCs.

The implemented Current-Source Active Filter was tested using similar conditions and loads of the simulations. Therefore the parameters of the experimental results can be seen in Table II. Both the Current-Source Active Filter, as the loads were connected to a $10 \mathrm{kVA}$ transformer with the voltages of $400 / / 200 \mathrm{~V}$, as has been done in the simulations.

As in the obtained computer simulations, it can be seen in Fig. 9 that the full-bridge rectifier consumes currents with high levels of distortion from the electrical grid. This way, the system voltages also present some distortion due to the line impedance and the fact that is feeding a nonlinear load. As shown in Fig. 10, after the Active Power Filter is turned-ON, it is possible to see that the source current $\left(i_{s a}\right)$ becomes almost sinusoidal. The power factor is nearly unitary, only not being unitary due to the capacitors of the inverter passive
- filters and due to the fact that the compensation currents are low.

The system voltages $\left(e_{s a}\right)$, as in the simulations, after the compensation acquire a high frequency component that is associated with the switching of the power semiconductors of the inverter.

In Fig. 11 is possible to see the DC-link inductance current, is also possible to see that the current is correctly regulated to $5 \mathrm{~A}$, and that only presents a ripple due to the load that the Current-Source Active Power Filter is compensating.

As in the simulations, Fig. 12 shows that the DC-link inductance presents voltage spikes in their terminals.

All the experimental results indicate that the developed Current-Source Active Power Filter is operating correctly when compensating a nonlinear load (composed by a fullbridge rectifier), contributing to mitigate the Power Quality problems associated with this type of load.

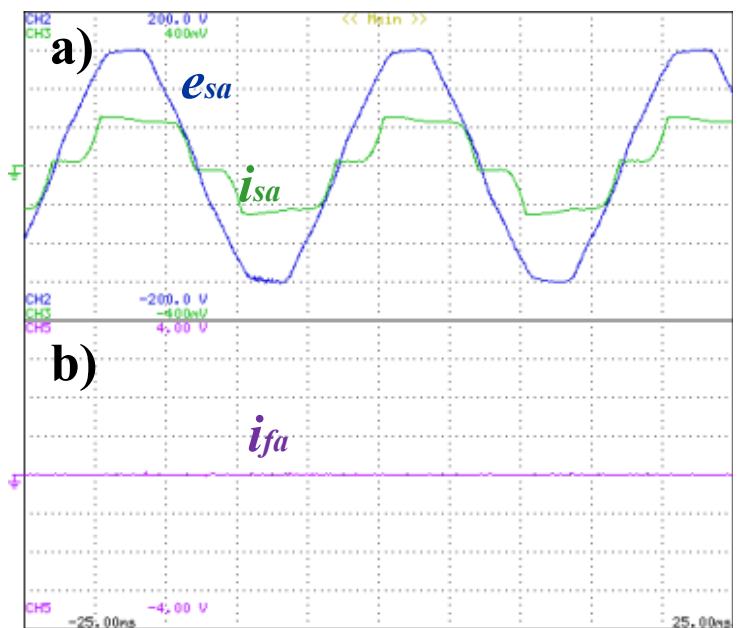

Fig. 9. Experimental results of the voltage $\left(e_{s a}\right)(50 \mathrm{~V} /$ div. $)$ and source current $\left(i_{s a}\right)(5 \mathrm{~A} / \mathrm{div})$ before the compensation $(\mathrm{a})$; inverter produced current (5 A/div.) (b) (5ms/div.).

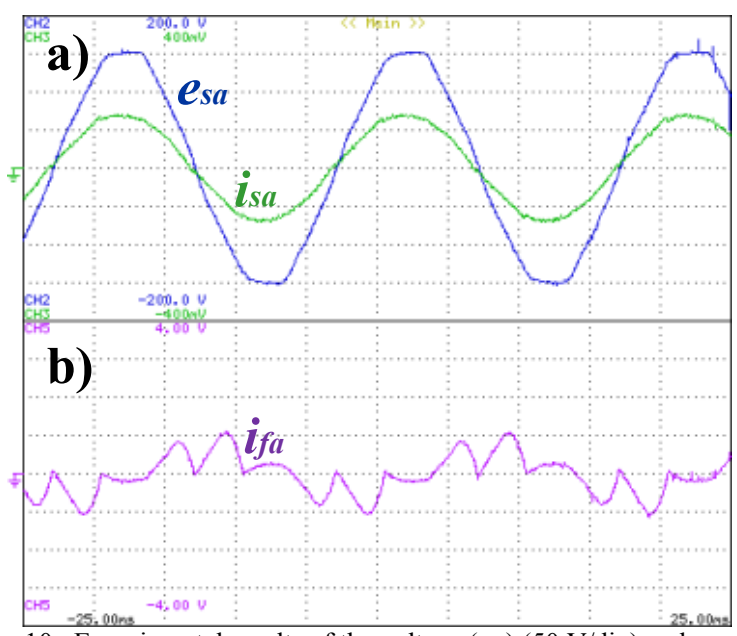

Fig. 10. Experimental results of the voltage $\left(e_{s a}\right)(50 \mathrm{~V} /$ div) and source current $\left(i_{s a}\right)(5 \mathrm{~A} / \mathrm{div})$ after the compensation $(\mathrm{a})$; inverter produced current (5 A/div) (b) (5ms/div.). 


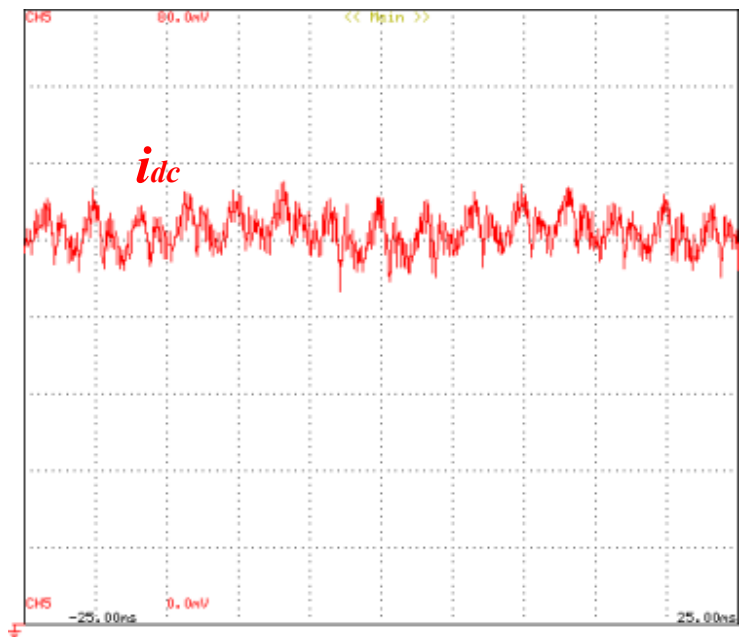

Fig. 11. Experimental results of the DC-link reference current $\left(i_{d c}\right)(1 \mathrm{~A} / \mathrm{div})$ (5ms/div.).

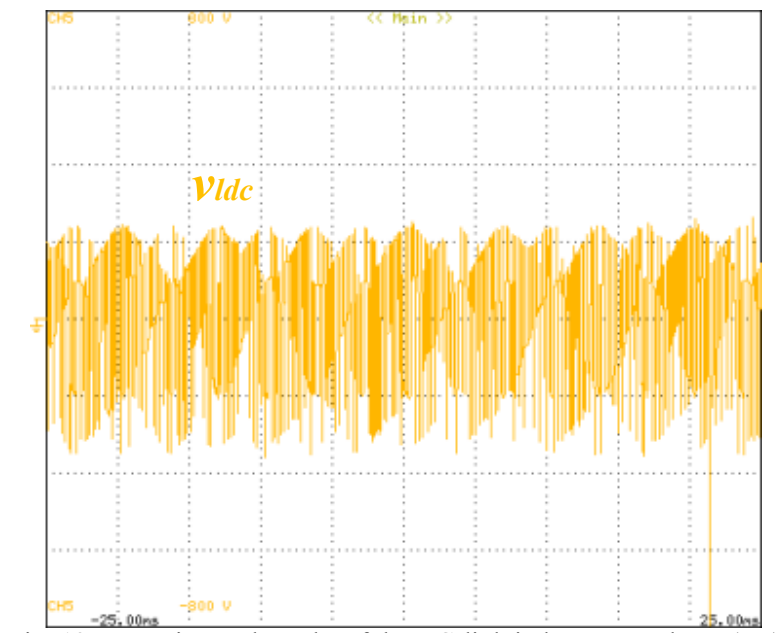

Fig. 12. Experimental results of the DC-link inductance voltage $\left(v_{l d c}\right)$ $(200 \mathrm{~V} /$ div. $)(5 \mathrm{~ms} /$ div. $)$

\section{CONCLUSIONS}

In this paper were presented simulation and experimental results of a Current-Source Shunt Active Power Filter operating with Periodic-Sampling modulation technique. The Active Filter performs well when compensating the load harmonics. The $p-q$ Theory performs well in the calculation of the reference compensating currents.

The experimental results obtained with a developed prototype, compensating a nonlinear load, validate the results obtained through simulation. It is possible to observe, in both simulation and experimental results, that the DC-link current of the Shunt Active Power Filter is correctly controlled by the implemented PI controller.

\section{ACKNOWLEDGMENT}

This work is financed by FEDER Funds, through the Operational Programme for Competitiveness Factors COMPETE, and by National Funds through FCT -
Foundation for Science and Technology of Portugal, under the projects: PTDC/EEA-EEL/104569/2008 and FCOMP-010124-FEDER-022674.

\section{REFERENCES}

[1] L. Energy, "Poor Power Quality costs European business more than $€ 150$ billion a year," 2008

[2] E. C. Strycula, L. Gyugyi, "Active AC Power Filters," in Proc. IEEE IIAS Ann. Mtg., 1976, pp. 529-535.

[3] B. Singh, K. Al-haddad, and A. Chandra, "A Review of Active Filters for Power Quality Improvement,” October, vol. 46, no. 5, pp. 960-971, 1999.

[4] M. El-Habrouk, M. K. Darwish, and P. Mehta, "Active power filters: A review," IEE Proceedings - Electric Power Applications, vol. 147, no. 5, p. 403, 2000.

[5] R. E. José and G. Joós, "A Current-Source-Inverter-Fed Induction Motor Drive System with Reduced Losses," IEEE Transactions on Industry Applications, vol. 34, no. 4, pp. 796-805, 1998.

[6] C. J. Ramos, P. Moreira, and A. Carvalho, "Current source inverter for a $400 \mathrm{~kW}$ ocean waves induction generator," EPE 99 - European Conference on Power Electronics and Applications, vol. 855, no. 1, pp. 172-180, 1999

[7] Y. Hayashi, N. Sato, and K. Takahashi, "A Novel Control of a CurrentSource Active Filter for ac Power System Harmonic Compensation," IEEE Transactions on Industry Applications, vol. 27, no. 2, pp. 380$385,1991$.

[8] M. Routimo, M. Salo, and H. Tuusa, "Comparison of Voltage-Source and Current-Source Shunt Active Power Filters," IEEE Transactions on Power Electronics, vol. 22, no. 2, pp. 636-643, 2007.

[9] M. H. Rashid, Power Electronics Handbook. Academic Press, 2001

[10] J. W. Dixon, T. M. Sebastian, and L. M. T, "Analysis and evaluation of different modulation techniques for active power filters," Electrical Engineering, 1994.

[11] B. Exposto, H. Carneiro, G. Pinto, C. Couto, and J. L. Afonso, "Simulations of a current-source Shunt Active Power Filter with Carrier-Based PWM and Periodic Sampling modulation techniques," in Power Electronics and Applications EPE 2011 Proceedings of the 201114th European Conference on, 2011, pp. 1-8.

[12] H. Akagi, Y. Kanazawa, and A. Nabae, "Generalized Theory of the Instantaneous Reactive Power in Three-Phase Circuits," in IPEC'83 Int. Power Electronics Conf., 1983, pp. 1375-1386.

[13] E. H. Watanabe and H. Akagi, "The p-q Theory for Active Filter Control: Some Problems and Solutions," Sba Controle \& Automação, vol. 15 , no. 1. Campinas, p. vol. 5 n. ${ }^{\circ} 5,2004$.

[14] J. Afonso, C. Couto, and J. Martins, "Active Filters with Control Based on the p-q Theory," IEEE Industrial Electronics Society newsletter, vol. 47 , pp. 5-10, 2000.

[15] E. H. Watanabe, M. Aredes, J. L. Afonso, J. G. Pinto, L. Monteiro, and H. Akagi, "Instantaneous p-q power theory for control of compensators in micro-grids," 2010 International School on Nonsinusoidal Currents and Compensation, pp. 17-26, Jun. 2010. 